\title{
Peep titration based on the open lung approach during one lung ventilation in thoracic surgery: a physiological study
}

Michela Rauseo ${ }^{1,5^{*}} \mathbb{D}$, Lucia Mirabella ${ }^{1}$, Salvatore Grasso ${ }^{2}$, Antonella Cotoia ${ }^{1}$, Savino Spadaro ${ }^{3}$, Davide D'Antini ${ }^{1}$, Franca Valentino ${ }^{1}$, Livio Tullo ${ }^{1}$, Domenico Loizzi ${ }^{4}$, Francesco Sollitto ${ }^{4}$ and Gilda Cinnella ${ }^{1}$

\begin{abstract}
Background: During thoracic surgery in lateral decubitus, one lung ventilation (OLV) may impair respiratory mechanics and gas exchange. We tested a strategy based on an open lung approach (OLA) consisting in lung recruitment immediately followed by a decremental positive-end expiratory pressure (PEEP) titration to the best respiratory system compliance $\left(C_{R S}\right)$ and separately quantified the elastic properties of the lung and the chest wall. Our hypothesis was that this approach would improve gas exchange. Further, we were interested in documenting the impact of the OLA on partitioned respiratory system mechanics.
\end{abstract}

Methods: In thirteen patients undergoing upper left lobectomy we studied lung and chest wall mechanics, transpulmonary pressure $\left(\mathrm{P}_{\mathrm{L}}\right)$, respiratory system and transpulmonary driving pressure $\left(\Delta \mathrm{P}_{R S}\right.$ and $\left.\Delta \mathrm{P}_{\mathrm{L}}\right)$, gas exchange and hemodynamics at two time-points (a) during OLV at zero end-expiratory pressure (OLV pre-OLA) and (b) after the application of the open-lung strategy (OLV post-OLA).

Results: The external PEEP selected through the OLA was $6 \pm 0.8 \mathrm{cmH}_{2} \mathrm{O}$. As compared to OLV pre-OLA, the $\mathrm{PaO}_{2} / \mathrm{FiO}_{2}$ ratio went from $205 \pm 73$ to $313 \pm 86(p=.05)$ and $C_{L}$ increased from $56 \pm 18 \mathrm{ml} / \mathrm{cmH}_{2} \mathrm{O}$ to $71 \pm 12 \mathrm{ml} / \mathrm{cmH}_{2} \mathrm{O}$ $(p=.0013)$, without changes in $C_{\mathrm{CW}}$.

Both $\Delta \mathrm{P}_{\mathrm{RS}}$ and $\Delta \mathrm{P}_{\mathrm{L}}$ decreased from $9.2 \pm 0.4 \mathrm{cmH}_{2} \mathrm{O}$ to $6.8 \pm 0.6 \mathrm{cmH}_{2} \mathrm{O}$ and from $8.1 \pm 0.5 \mathrm{cmH}_{2} \mathrm{O}$ to $5.7 \pm 0.5$ $\mathrm{CmH}_{2} \mathrm{O},(\mathrm{p}=.001$ and $p=.015$ vs OLV pre-OLA), respectively. Hemodynamic parameters remained stable throughout the study period.

Conclusions: In our patients, the OLA strategy performed during OLV improved oxygenation and increased $C_{L}$ and had no clinically significant hemodynamic effects. Although our study was not specifically designed to study $\Delta \mathrm{P}_{\mathrm{RS}}$ and $\Delta \mathrm{P}_{\mathrm{L}}$, we observed a parallel reduction of both after the OLA.

Trial registration: TRN: ClinicalTrials.gov, NCT03435523, retrospectively registered, Feb 142018.

Keywords: One lung ventilation, Recruitment maneuver, Thoracic surgery, Open lung approach

\footnotetext{
* Correspondence: michela.rauseo@hotmail.it

'Department of Anesthesia and Intensive care, University of Foggia, Viale

Pinto, 1-71100 Foggia, Italy

${ }^{5}$ Interdepartmental Division of Critical Care Medicine, University of Toronto,

Toronto, ON, Canada

Full list of author information is available at the end of the article
}

(c) The Author(s). 2018 Open Access This article is distributed under the terms of the Creative Commons Attribution 4.0 International License (http://creativecommons.org/licenses/by/4.0/), which permits unrestricted use, distribution, and reproduction in any medium, provided you give appropriate credit to the original author(s) and the source, provide a link to the Creative Commons license, and indicate if changes were made. The Creative Commons Public Domain Dedication waiver (http://creativecommons.org/publicdomain/zero/1.0/) applies to the data made available in this article, unless otherwise stated. 


\section{Background}

During one-lung ventilation (OLV) in the lateral decubitus position for thoracic surgery, hypoxemia may occur in almost $10 \%$ of patients [1-3], due to the total collapse of the non-dependent lung and, eventually, to atelectasis in the ventilated, dependent lung $[4,5]$. We recently demonstrated [6] that a recruitment strategy applied to the dependent lung followed by a moderate PEEP level results in significant alveolar recruitment, increased arterial oxygenation and reduction of the respiratory system elastance $\left(\mathrm{E}_{\mathrm{RS}}\right)$, without hemodynamic impairment. Our data are in agreement with reports from several physiological studies [7-10], however little is still known on how to perform recruitment and set PEEP in this context. Recent physiological data suggest that immediately after the recruitment maneuver (RM), PEEP should be titrated through a decremental trial, in order to optimize respiratory mechanics while minimizing alveolar over distension [11]. This approach, originally proposed for patients with Acute Respiratory Distress Syndrome (ARDS), is designated as the "open lung approach" (OLA). Its physiological rationale is that alveolar recruitment is a pan-inspiratory phenomenon, so that a maximal inflation is needed to reverse lung atelectasis. Furthermore, due to the hysteresis between the inspiratory and expiratory volume-pressure curve, in the OLA approach, PEEP is titrated in the expiratory limb of the respiratory system volume-pressure curve, immediately after obtaining the maximal recruitment $[11,12]$.

A key point in understanding the effects of the OLA strategy is the partitioning between lung and chest wall mechanical properties, through the measurement of transpulmonary pressure $\left(\mathrm{P}_{\mathrm{L}}\right)$, i.e. the lung distending pressure: in clinical conditions, $\mathrm{P}_{\mathrm{L}}$ allows to evaluate the influence of chest wall mechanics on lung volumes and airway pressures. For a given airway opening pressure $\left(\mathrm{P}_{\mathrm{AO}}\right)$, pleural pressure $\left(\mathrm{P}_{\mathrm{PL}}\right)$ varies depending on the amount of lung compression exerted by the chest wall [13]. Therefore, when the chest wall compression rises, $\mathrm{P}_{\mathrm{L}}$ drops and lungs may be underinflated, independently from the level of $\mathrm{P}_{\mathrm{AO}}$ [14]. We recently demonstrated that OLA applied during laparoscopic surgery was associated with a significant increase in $\mathrm{P}_{\mathrm{L}}$ and improvement in gas exchange, suggesting that PEEP and transpulmonary pressure are important determinants of respiratory mechanics [15].

The measurement of lung and chest wall response to the OLA may thus be of interest during OLV, since a multiplicity of factors may account for the alveolar derecruitment that usually develops in the dependent lung during OLV, such as the underlying lung parenchymal disease, the loss of chest wall elastic recoil, the lateral decubitus usually with a $15-20^{\circ}$ posterior rotation of the coxa [2], the surgical manoeuvres [4], the mediastinum weight and the ventilatory set up used [16-18].
Our study was thus launched to evaluate the effect on oxygenation and on lung and chest wall mechanics of the OLA applied on the dependent lung during thoracic surgery.

\section{Methods}

After approval of the local ethics committee and written informed consent from each patient, the study was performed in consecutive patients scheduled to undergo elective lung lobectomy or resection through thoracotomy requiring OLV in the right lateral position, from February to November 2012 (ClinicalTrials.gov: NCT03435523). Inclusion criteria were age $>18$ years, surgery and OLV lasting $\geq 60 \mathrm{~min}$. Exclusion criteria were lung reduction surgery, pneumonectomy, patients with severe COPD with preoperative forced expiratory volume in $1 \mathrm{~s}\left(\mathrm{FEV}_{1}\right)$ to forced vital capacity $(\mathrm{FVC})$ ratio, expressed as a percentage $\left(\mathrm{FEV}_{1} / \mathrm{FVC} \%\right)<60 \%$, presence of large bullae, pleural diseases and/or acute or chronic uncompensated cardiac disease.

Upon their arrival in the operating room, patients were pre-medicated with midazolam $0.03-0.04 \mathrm{mg} / \mathrm{kg}$. After applying standard monitoring device [electrocardiogram and pulse oximeter (Intellivue MP40 monitor, Philips, Boeblingen, Germany)], radial artery was cannulated (Radial Artery Catheterization Set, Arrow International, Reading, PA, USA) and the cannula was connected to the FloTrac $^{\text {тм }}$ sensor and the Vigileo $^{\text {тм }}$ monitor (Edwards Life Sciences LLC, Irwine, CA, USA, software version 01.10), which, in addition to arterial pressure transduction, allowed stroke volume (SV) and stroke volume variation (SVV) estimation from the arterial pressure waveform. The level of anesthesia was assessed through bi-spectral index (BIS) monitoring (Aspect A-2000 ${ }^{\circ}$; Aspect Medical System, Newton, MA). Patients were given a bolus of $8 \mathrm{ml} / \mathrm{kg}$ of normal saline IV before the induction of anesthesia and were then maintained with $5 \mathrm{ml} /$ $\mathrm{kg} / \mathrm{h}$ of normal saline solution. A standardized protocol for hemodynamic management was applied in order to assure fluid volume optimization [16, 17]. Briefly, if SVV was lower than $13 \%$, no additional fluids were given whereas if SVV was higher 13\%, additional boluses of $250 \mathrm{ml}$ of artificial colloid were infused over 15-20 min. After each bolus SVV was re-evaluated, and a further bolus was administered if SV increased by more than $10 \%$, until reaching a SVV lower than $13 \%$.

Anesthesia was induced with propofol $2 \mathrm{mg}^{*} \mathrm{~kg}^{-1}$, fentanyl $3 \gamma^{*} \mathrm{~kg}^{-1}$, and succinylcholine $1 \mathrm{mg}^{*} \mathrm{~kg}^{-1}$. Anesthesia was maintained with an infusion of propofol $150-200 \gamma^{*} \mathrm{~kg}^{-1 *} \mathrm{~min}^{-1}$, remifentanil $0.1-0.2 \gamma^{*} \mathrm{~kg}$ ${ }^{-1}{ }^{*} \mathrm{~min}^{-1}$ and cisatracurium $1.5 \gamma^{*} \mathrm{~kg}^{-1_{*}} \mathrm{~min}^{-1}$. The infusion rate of propofol was varied in order to target a BIS value between 50 and 60 . 
After induction, the trachea and left bronchus were intubated with a left double lumen tube (DLT) of the appropriate size (Rushelit Rush AG lab, Waiblingen, Germany). Correct DLT position was checked using fiber optic bronchoscopy and confirmed after turning the patients in the lateral position. At OLV time, the lumen of the non-ventilated lung was left open to atmosphere. The lungs were ventilated using a Fabius GS Premium (Drager, Lubeck, Germany) with a square flow waveform. Ventilation was set for a tidal volume (Vt) of $6-8 \mathrm{ml}^{*} \mathrm{~kg}^{-1} \mathrm{PBW}$, respiratory rate (RR) of 1214 breath $/ \mathrm{min}$, inspiratory time $(\mathrm{Ti})$ of $33 \%$ without inspiratory pause. Patients were initially ventilated using oxygen in air with an inspiratory oxygen fraction $\left(\mathrm{FiO}_{2}\right)$ as needed to maintain the $\mathrm{SaO} 2>95 \%$. No PEEP was initially added. During OLV the Vt was reduced by $30 \%$ from starting value, increasing respiratory rate as needed, while all the other parameter were kept constant [6].

\section{Study protocol (Fig.1)}

When OLV was started, after assuring that patients were hemodynamically stable (i.e. mean arterial blood pressure, $\mathrm{mBP} \geq 80 \mathrm{mmHg}, \mathrm{HR} \geq 60 \mathrm{~b} / \mathrm{min}$ ) and that the preload index continued to be adequate (i.e. SVV $\leq 13 \%$ ), the recruitment manoeuver was applied selectively to the ventilated lung as already described $[6,13,18,19]$. In summary, the ventilator was switched to pressure-control ventilation with an inspiratory pressure of $20 \mathrm{cmH}_{2} \mathrm{O}$ above PEEP. After a 3 min equilibration, PEEP was applied in steps of 5,10,15 and $20 \mathrm{cmH}_{2} \mathrm{O}$ every five respiratory breaths; the maximal recruiting pressure of $40 \mathrm{cmH}_{2} \mathrm{O}$ (20 PEEP/20 driving pressure) was applied for six breaths. Subsequently, after setting an inspiratory pressure of 15 $\mathrm{cmH}_{2} \mathrm{O}$ above PEEP, PEEP was stepwise reduced, starting from $15 \mathrm{cmH}_{2} \mathrm{O}$, by $2 \mathrm{cmH}_{2} \mathrm{O}$ every $2 \mathrm{~min}$. During the decremental PEEP trial, static $C_{\mathrm{RS}}$ was measured at every step, through end inspiratory and end expiratory occlusions. The PEEP level corresponding to highest $\mathrm{C}_{\mathrm{RS}}$ during the decremental trial was identified as the "best PEEP". Subsequently, the lungs were recruited again and the "best" PEEP was applied. The ventilator was then switched to volume-control ventilation maintaining the baseline settings, except that for the "best" PEEP level. This setting was maintained until the end of surgery.

Hemodynamic, gas exchange and respiratory mechanics measurements were obtained in two steps, before surgery, with the chest wall closed: a) on OLV in the lateral decubitus before applying the open lung approach $\left(\mathrm{OLV}_{\text {pre-OLA }}\right)$, and, b) $20 \mathrm{~min}$ after applying the open lung approach $\left(\mathrm{OLV}_{\text {post-OLA }}\right)$.

\section{Measurements}

Blood pressure (BP) was measured through a radial catheter connected to the pressure transducer of the MP40 monitor. Hemodynamic parameters obtained through the Vigileo included SV, cardiac output (CO), and stroke volume variation (SVV) whereas stroke volume index (SVI) and cardiac index (CI) were calculated using standard formulae. All intravascular pressure measurements were zeroed to the mid-axillary line. Analysis of arterial blood gases was performed (ABL 330; Radiometer, Copenaghen, Denmark).

Respiratory mechanics parameters were recorded, digitized and collected on a personal computer through a 12-bit analog-to digital converter board (DAQCard 700; National Instrument, Austin, TX) at a sample rate of $200 \mathrm{~Hz}$ (ICU Lab, KleisTEK Engineering, Bari, Italy).

Flow was measured with a heated pneumotachograph (Fleisch no.2; Fleisch, Lausanne, Switzerland), connected to a differential pressure transducer (Diff-Cap, $\pm 1 \mathrm{cmH} 20$; Special Instruments, Nordlingen, Germany) inserted between the Y-piece of the ventilator circuit and the endotracheal tube. The pneumotachograph was linear over the experimental range of flow. Volume was obtained by numerical integration of the flow signal. $\mathrm{P}_{\mathrm{AO}}$ was measured proximal to the endotracheal tube with a pressure transducer (Special Instruments Digima-Clic \pm 100 cmH20; Nordlingen, Germany). The difference between the level of the PEEP set on the ventilator (read as the $\mathrm{P}_{\mathrm{AO}}$ value at the end of a regular breath) (PEEP $\left.\mathrm{external}\right)$ and the pressure in $\mathrm{P}_{\mathrm{AO}}$ during a 3-5 s end-expiratory occlusion ( $\left.\mathrm{PEEP}_{\mathrm{TOT}}, \mathrm{RS}\right)$ was measured and regarded as the static intrinsic PEEP of the respiratory system (PEEPi $\left.i_{R S}\right)$ according to Pepe [14].

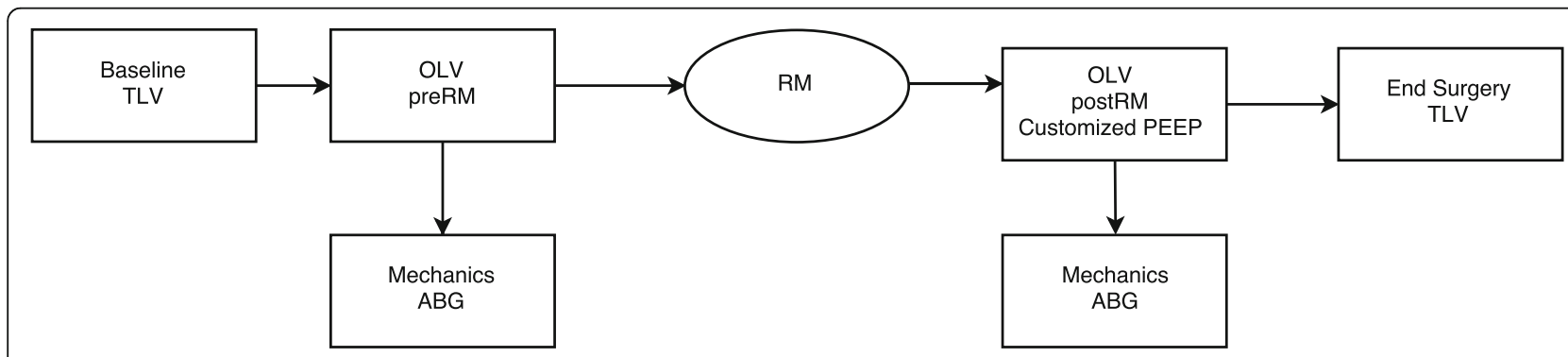

Fig. 1 Study protocol 
$\mathrm{P}_{\mathrm{PL}}$ was estimated by measurement of esophageal pressure $\left(\mathrm{P}_{\text {eso }}\right)$, by a thin latex balloon-tipped catheter connected via a polyethylene catheter to a pressure transducer (Special Instrument DigimaClic $\pm 100 \mathrm{cmH} 2 \mathrm{O}$; Nordlingen, Germany). The esophageal balloon was filled with $1-1.5 \mathrm{ml}$ of air and the correct position of the probe was verified on the computer software of recording and analysis (ICU Lab, KleisTEK Engineering, Bari, Italy) according to the literature [20-24].

The end-inspiratory and end-expiratory occlusions were performed through the inspiratory and expiratory holds on the Fabius GS Premium ventilator.

Total positive end expiratory pressure $\left(\mathrm{PEEP}_{\mathrm{TOT}}\right), \mathrm{P}_{\mathrm{AO}}$, $\mathrm{P}_{\mathrm{PLAT}}, \mathrm{P}_{\mathrm{L}}, \mathrm{C}_{\mathrm{RS}}, \mathrm{C}_{\mathrm{L}}, \mathrm{C}_{\mathrm{CW}}, \Delta \mathrm{P}_{\mathrm{RS}}$ and $\Delta \mathrm{P}_{\mathrm{L}}$ were measured as previously described [15].

\section{Statistical analysis}

A sample size calculation was performed using data from our previous study [6] on the effects of recruiting maneuvers on $\mathrm{C}_{\mathrm{RS}}$ and $\mathrm{PaO}_{2} / \mathrm{FiO}_{2}$ in patients undergoing OLV for thoracic surgery. Based on these data, the significant change in $\mathrm{C}_{\mathrm{RS}}$ before and after the recruitment maneuver was designated as a $25 \% \mathrm{C}_{\mathrm{RS}}$ increase with a $\mathrm{SD}$ of 8.9 and the improvement in $\mathrm{PaO}_{2} / \mathrm{FiO}_{2}$ as a ratio increase of 115 with a SD of 120 . The larger sample size of 13 patients resulted from the $\mathrm{P} / \mathrm{F}$ ratio and was used for patients' enrollment. The $\alpha$ and $\beta$ errors for the sample size were chosen as 0.05 and 0.90 respectively $[25,26]$. Statistical comparison of respiratory mechanics, hemodynamic and gas exchange data was performed between the two study steps: data were tested for normal distribution by the Kolmogorov-Smirnov goodness- of -fit test and presented as mean $( \pm S D)$. Paired T-test analysis was performed between $\mathrm{OLV}_{\text {pre-OLA }}$ and $\mathrm{OLV}_{\text {post-OLA }}$ to evaluate the effect of the recruitment maneuvers on respiratory mechanics, hemodynamic and gas exchange. A $p$ value $<0.05$ was considered statistically significant. Data are presented as mean \pm SD. Statistical analysis was performed using the software Statistica 10.0 (Statsoft Italia srl 2011).

\section{Results}

Thirteen out of 24 patients initially evaluated for enrolment were included in the study. The enrolment flow diagram is reported in Fig. 2. The mean external PEEP

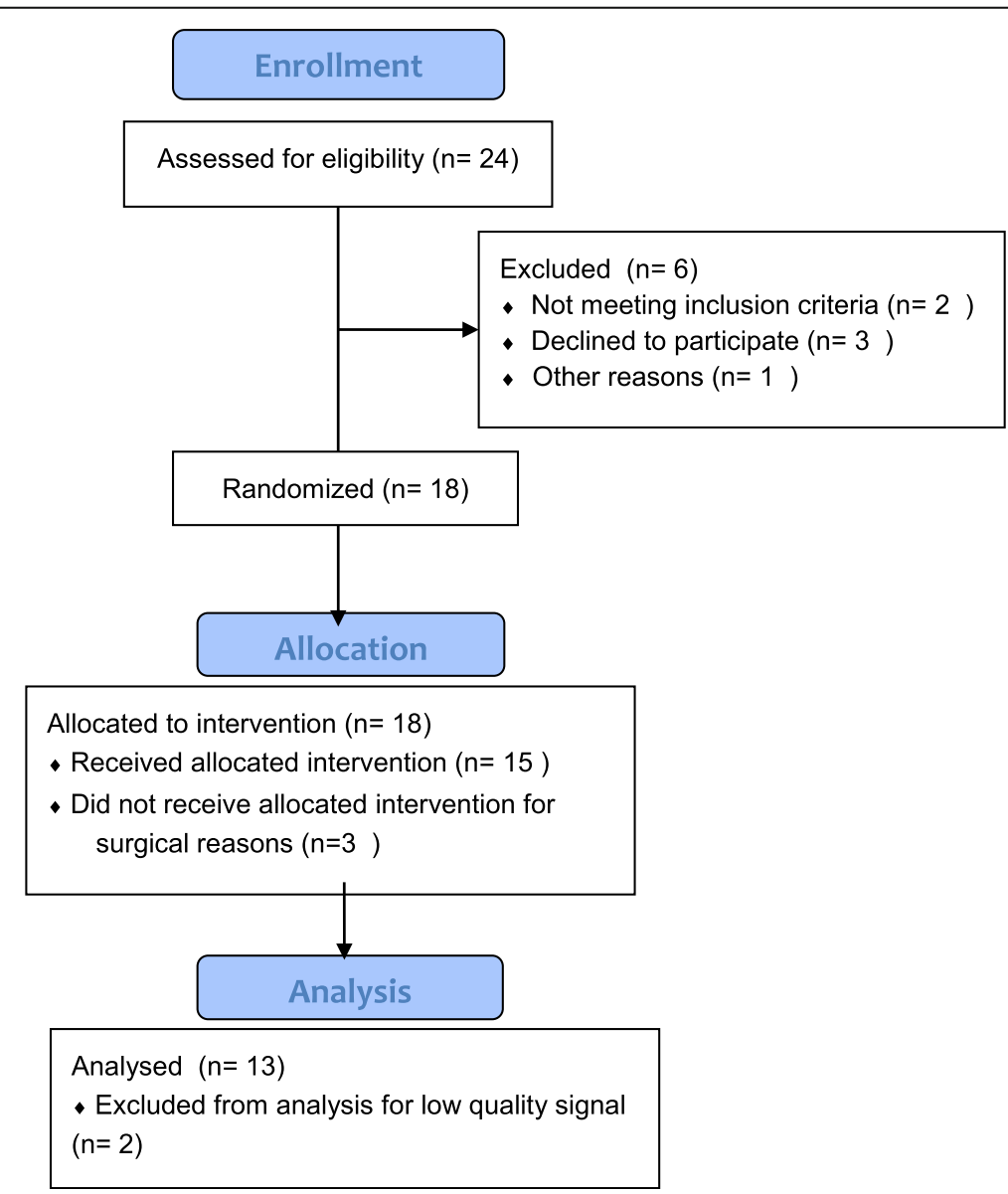

Fig. 2 CONSORT flow chart 
resulting from the decremental PEEP titration after the $\mathrm{RM}$ was $6 \pm 0.8 \mathrm{cmH}_{2} \mathrm{O}$ (range $5-8 \mathrm{cmH}_{2} \mathrm{O}$ ).

Demographic characteristics and baseline spirometric data of the population studied are presented in Table 1. The study was completed successfully in all the patients without protocol-related complications or adverse events.

None of the patients was affected by postoperative pulmonary complications.

Hemodynamic parameters remained unchanged throughout the study despite a transient decrease in $\mathrm{CI}$ and MAP during the RM (Table 2).

Table 3 shows the main respiratory mechanics and gas exchange parameters throughout the study (data are expressed as mean $\pm \mathrm{SD}$ ). On OLV pre-OLA the $\mathrm{PaO}_{2} / \mathrm{FiO}_{2}$ ratio was $205 \pm 73$ and improved to $313 \pm 86(p=0.05)$ on $\mathrm{OLV}_{\text {post-OLA }}$ while $\mathrm{PaCO}_{2}$ and $\mathrm{pH}$ remained unchanged.

Both $\mathrm{C}_{\mathrm{RS}}$ and $\mathrm{C}_{\mathrm{L}}$ significantly increased from $45 \pm 11 \mathrm{ml} /$ $\mathrm{cmH}_{2} \mathrm{O}$ to $62 \pm 13 \mathrm{ml} / \mathrm{cmH}_{2} \mathrm{O}$ and from $56 \pm 18 \mathrm{ml} /$ $\mathrm{cmH}_{2} \mathrm{O}$ to $71 \pm 12 \mathrm{ml} / \mathrm{cmH}_{2} \mathrm{O} \quad(p=0.001, p=0.0013$, vs $\mathrm{OLV}_{\text {pre-OLA }}$, respectively), while $\mathrm{C}_{\mathrm{CW}}$ did not change.

Airway resistance (Raw) went from $11.24 \pm 3.72 \mathrm{cmH}_{2} \mathrm{O} /$ $\mathrm{L} / \mathrm{s}$ to $7.42 \pm 4.21 \mathrm{cmH}_{2} \mathrm{O} / \mathrm{L} / \mathrm{s} . \Delta \mathrm{P}_{\mathrm{RS}}$ and $\Delta \mathrm{P}_{\mathrm{L}}$ decreased after the OLA from $9.2 \pm 0.4 \mathrm{cmH}_{2} \mathrm{O}$ to $6.9 \pm 0.6 \mathrm{cmH}_{2} \mathrm{O}$ and from $8.1 \pm 0.5 \mathrm{cmH}_{2} \mathrm{O}$ to $5.7 \pm 0.5 \mathrm{cmH}_{2} \mathrm{O}$ respectively $\left(p=0.001\right.$ and $p=0.015$ vs $\left.\mathrm{OLV}_{\text {pre}^{-} \mathrm{OLA}}\right)$.

\section{Discussion}

The main result of the present study is that during OLV in lateral decubitus, the application of an open lung strategy consisting in a RM followed by a decremental PEEP titration significantly improves oxygenation and lung mechanical properties without significant hemodynamic effects.
It is well acknowledged that OLV in lateral decubitus may induce a "multiple-hit" mechanism for lung injury: on one side the dependent lung is prone to mechanical damage due to intratidal cyclic parenchymal opening and closing, compression by mediastinal structures, surgical manipulations and loss of elastic recoil, on the other there is the collapse and re-expansion of the non dependent lung [27]. Moreover, the reduction of aerated lung capacity may worsen the ventilation-to-perfusion matching that could result in a significant gas exchange impairment $[28,29]$. The common ventilatory setting to counterbalance hypoxemia during OLV used to include $\mathrm{Vt}$ as high as during two-lungs ventilation (i.e. 8 to $10 \mathrm{ml} / \mathrm{Kg}$ ) [7, 30-32] and PEEP as a rescue therapy in case of severe hypoxemia, in selected patients. Recent studies, however, demonstrated that large Vts do exacerbate the risk for Ventilator-Induced Lung Injury (VILI) through the enhancement of oxidative and inflammatory reactions [33], whereas a lung-protective ventilatory strategy with smaller Vt and PEEP applied after appropriate lung recruitment on the dependent lung during OLV minimizes VILI, resulting in less postoperative lung complications [34-38], and increases oxygenation [9, 18, $19,28]$. However, very low Vts as the one suggested for ventilating the dependent lung during OLV $(4-5 \mathrm{ml} / \mathrm{Kg})$ may per se induce alveolar de-recruitment unless an "adequate" PEEP level is set. Unfortunately, there is no agreement on the correct PEEP setting in the OLV context. In a recent study, Spadaro and coworkers documented the physiological interplay between very low Vts and two PEEP levels (5 and $10 \mathrm{cmH}_{2} \mathrm{O}$ ) on oxygenation, respiratory mechanics and ventilation/perfusion

Table 1 Patients demographic characteristics

\begin{tabular}{|c|c|c|c|c|c|c|c|c|c|c|c|}
\hline $\begin{array}{l}\text { Patient } \\
\text { No }\end{array}$ & $\begin{array}{l}\text { Age } \\
(y r)\end{array}$ & Sex & $\begin{array}{l}\mathrm{BMI} \\
\left(\mathrm{Kg} / \mathrm{m}^{2}\right)\end{array}$ & ASA & $\mathrm{pH}$ & $\begin{array}{l}\mathrm{PaO}_{2} \\
(\mathrm{mmHg})\end{array}$ & $\begin{array}{l}\mathrm{PaCO}_{2} \\
(\mathrm{mmHg})\end{array}$ & $\begin{array}{l}\mathrm{FEV}_{1} \\
\text { (\% Pred) }\end{array}$ & $\begin{array}{l}\mathrm{FEV}_{1} / \mathrm{FVC} \\
(\%)\end{array}$ & Surgery & $\begin{array}{l}\text { Duration } \\
\text { (min) }\end{array}$ \\
\hline 1 & $60-69$ & 2 & 21.6 & 2 & 7.31 & 73 & 53 & 42 & 67 & Left upper lobectomy & 75 \\
\hline 2 & $50-59$ & 2 & 19.64 & 4 & 7.43 & 76 & 43 & 55 & 67 & Left upper lobectomy & 65 \\
\hline 3 & $60-70$ & 2 & 20.83 & 3 & 7.42 & 82 & 38 & 65 & 77 & Left upper lobectomy & 80 \\
\hline 4 & $50-60$ & 2 & 22.18 & 3 & 7.42 & 108 & 24 & 87 & 88 & Left upper lobectomy & 70 \\
\hline 5 & $60-70$ & 2 & 25.75 & 3 & 7.42 & 81 & 48 & 50 & 60 & Left upper lobectomy & 70 \\
\hline 6 & $50-60$ & 2 & 16.86 & 2 & 7.38 & 73 & 43 & 115 & 108 & Left upper lobectomy & 60 \\
\hline 7 & $50-60$ & 2 & 22.05 & 2 & 7.42 & 89 & 47 & 98.2 & 77 & Left upper lobectomy & 85 \\
\hline 8 & $50-60$ & 1 & 20.83 & 3 & 7.4 & 73 & 42 & 42 & 67 & Left upper lobectomy & 90 \\
\hline 9 & $40-50$ & 2 & 25.75 & 3 & 7.41 & 89 & 50 & 69 & 78 & Left upper lobectomy & 95 \\
\hline 10 & $70-80$ & 2 & 22.41 & 2 & 7.38 & 84 & 38 & 96 & 99 & Left upper lobectomy & 105 \\
\hline 11 & $60-70$ & 2 & 23.33 & 2 & 7.38 & 113 & 40 & 57 & 107 & Left upper lobectomy & 110 \\
\hline 12 & $60-70$ & 1 & 19.39 & 4 & 7.4 & 97 & 43 & 82 & 71 & Left upper lobectomy & 85 \\
\hline 13 & $50-60$ & 2 & 26.36 & 2 & 7.45 & 63 & 49 & 108 & 114 & Left upper lobectomy & 90 \\
\hline Mean & 59 & & 22.07 & & 7.4 & 86.4 & 42.6 & 86.6 & 82.3 & & 83.1 \\
\hline SD & 6.8 & & 2.75 & & 0.03 & 16.2 & 6.15 & 22.5 & 19.43 & & 17.35 \\
\hline
\end{tabular}


Table 2 Hemodynamic parameters during the different experimental conditions

\begin{tabular}{|c|c|c|c|c|c|c|}
\hline & TLV Baseline & OLV preOLA & During RM & OLV postOLA & TLV end & ANOVA \\
\hline $\mathrm{HR}(\mathrm{b} / \mathrm{m})$ & $76 \pm 14$ & $77 \pm 12$ & $80 \pm 11$ & $76 \pm 13$ & $75 \pm 12$ & N.S. \\
\hline MAP $(\mathrm{mmHg})$ & $91 \pm 12$ & $86 \pm 15$ & $82 \pm 10 *$ & $88 \pm 14$ & $90 \pm 11$ & $P<0.05$ \\
\hline $\mathrm{Cl}\left(1 / \mathrm{m}^{2}\right)$ & $2.7 \pm 0.4$ & $3.1 \pm 0.9$ & $2.4 \pm 0.3^{*}$ & $2.8 \pm 0.4$ & $3.0 \pm 0.2$ & $P<0.05$ \\
\hline SW (\%) & $12 \pm 2$ & $13 \pm 1$ & $13 \pm 2$ & $13 \pm 2$ & $14 \pm 1$ & N.S. \\
\hline
\end{tabular}

ANOVA * $P<0.05$ TLV baseline vs RM

$H R$ heart rate, MAP mean arterial blood pressure, $C I$ cardiac index, SVV stroke volume variation, $T L V$ two-lung ventilation, $O L V$ one-lung ventilation, $R M$ recruitment manoeuvre. Data are expressed as mean \pm SD

mismatch during OLV. Their findings were that in this setting only a relatively high PEEP level $\left(10 \mathrm{cmH}_{2} \mathrm{O}\right)$ guarantees improvement of gas exchange, shunt reduction and improvement of respiratory mechanics [39]. In the present study we found that lower PEEP levels, i.e. $6 \pm 0.8 \mathrm{cmH}_{2} \mathrm{O}$ (range $5-8 \mathrm{cmH}_{2} \mathrm{O}$ ) were able to improve oxygenation and lung mechanics. The apparent discrepancy between ours and Spadaro's data could be explained by the different design of the two studies. Indeed, we applied a complete lung recruitment and individualized PEEP titration strategy whereas Spadaro studied two fix PEEP levels were applied without previous maximal lung recruitment. Our study seems to confirm that in the OLV context, similarly than in early ARDS, a decremental PEEP titration trial is required to keep the lung fully opened after a maximal lung recruitment maneuver [40].

Table 3 Breathing pattern and gas exchange parameters during the different experimental conditions

\begin{tabular}{|c|c|c|c|}
\hline & $\mathrm{OLV}_{\text {pre-OLA }}$ & OLV $_{\text {post-OLA }}$ & $p$-value \\
\hline $\mathrm{V}_{\mathrm{T}}(\mathrm{ml} / \mathrm{Kg} \mathrm{PBW})$ & $5.9 \pm 0.9$ & $5.9 \pm 0.7$ & 0.47 \\
\hline RR (breaths/min) & $18 \pm 1$ & $18 \pm 1$ & 0.77 \\
\hline $\mathrm{P}_{\mathrm{AO}, \mathrm{PLAT}}\left(\mathrm{cmH}_{2} \mathrm{O}\right)$ & $12.8 \pm 1.6$ & $16.7 \pm 2.2^{*}$ & 0.003 \\
\hline PEEP ext $\left(\mathrm{cmH}_{2} \mathrm{O}\right)$ & 0 & $6 \pm 0.8$ & 0.3 \\
\hline PEEP TOT, RS $\left(\mathrm{cmH}_{2} \mathrm{O}\right)$ & $3.6 \pm 1.4$ & $9.8 \pm 1.2^{*}$ & 0.0001 \\
\hline$\Delta \mathrm{P}_{\mathrm{RS}}\left(\mathrm{cmH}_{2} \mathrm{O}\right)$ & $9.24 \pm 0.4$ & $6.88 \pm 0.6^{*}$ & 0.001 \\
\hline$\Delta \mathrm{P}_{\mathrm{L}}\left(\mathrm{cmH}_{2} \mathrm{O}\right)$ & $8.1 \pm 0.5$ & $5.7 \pm 0.5^{*}$ & 0.015 \\
\hline $\mathrm{C}_{\mathrm{RS}}\left(\mathrm{ml} / \mathrm{cmH}_{2} \mathrm{O}\right)$ & $45 \pm 11.3$ & $62 \pm 13.4^{*}$ & 0.001 \\
\hline $\mathrm{C}_{\mathrm{L}}\left(\mathrm{ml} / \mathrm{cmH}_{2} \mathrm{O}\right)$ & $56.17 \pm 18.18$ & $71.06 \pm 12.25^{*}$ & 0.0013 \\
\hline $\mathrm{C}_{\mathrm{cW}}\left(\mathrm{ml} / \mathrm{cmH}_{2} \mathrm{O}\right)$ & $310 \pm 15.4$ & $312 \pm 14.2$ & NS \\
\hline Raw $\left(\mathrm{cmH}_{2} \mathrm{O} / \mathrm{L} / \mathrm{s}\right)$ & $11.24 \pm 3.72$ & $7.42 \pm 4.21^{*}$ & 0.004 \\
\hline $\mathrm{pH}$ & $7.37 \pm 0.05$ & $7.37 \pm 0.03$ & NS \\
\hline $\mathrm{PaCO}_{2}(\mathrm{mmHg})$ & $44 \pm 2.9$ & $43 \pm 3.8$ & NS \\
\hline $\mathrm{PaO}_{2} / \mathrm{FiO}_{2}(\mathrm{mmHg})$ & $205 \pm 73$ & $313 \pm 86^{*}$ & 0.004 \\
\hline
\end{tabular}

Pared T-test was used for the comparison of continuous variables. Data are expressed as mean \pm SD

$C_{R S}$ respiratory system compliance, $C_{L}$ lung compliance, $C_{C W}$ chest wall compliance, $\Delta P_{R S}$ respiratory system driving pressure, $\Delta P_{L}$ transpulmonary driving pressure, $\mathrm{FiO}_{2}$ inspiratory oxygen fraction, $\mathrm{PaO}_{2}$ arterial oxygen tension, $\mathrm{PaCO}$ arterial carbon dioxide tension, $P E E P$ positive end expiratory pressure, $P E E P_{\text {ext }}$ external PEEP, PEEP $P_{T O T, R S}$ respiratory system total PEEP, $P_{A O, P L A T}$ respiratory system plateau airways pressure, $R R$ respiratory rate, $V_{T}$ tidal volume

statistical significant when compared to OLV $V_{\text {pre-OLA }}$
In a previous report, our group demonstrated that, besides the positive effect on gas exchange, the application of a RM followed by a standard PEEP of $5 \mathrm{mmHg}$ during OLV induces a reduction in $\mathrm{E}_{\mathrm{RS}}$ [6]. Recently, Ferrando et al. [11], showed that the improvement in $C_{R S}$, dead space and oxygenation during OLV was more noticeable in patients undergoing a PEEP titration after the RM. Actually, individualizing the level of PEEP required to maintain the lung open after the RM, is presently considered superior to the "one-size-fit-all" method of standardized PEEP in order to match that particular patients respiratory mechanical properties [41]. Currently, the appropriate method to select PEEP remains unclear, however the decremental PEEP titration method that we used in the present study and that lead to an average PEEP level of $6 \pm 0.8 \mathrm{cmH}_{2} \mathrm{O}$, is widely studied and relatively easy to perform at the bedside, even during anesthesia $[11,18,19]$. When compared to Ferrando et al. [11], we used the same recruitment maneuver and observed an improvement in gas exchange and $C_{R S}$. The novelty of our study is that we partitioned lung and chest wall mechanics response to the OLA strategy, which allowed to highlight how this response is attributable mainly to the lung component. In literature, an amount of data confirm that the dependent hemithorax is compressed in lateral position: actually, the static $\mathrm{P} / \mathrm{V}$ curve of the lungs has a rightward horizontal shift in lateral decubitus as compared to the upright position (i.e. about $15 \%$ less compliant), with a similar slope [42]. By separately measuring the $C_{R S}$ of both hemithoraces, Klingsted et al. [43], in a seminal paper demonstrated that the $\mathrm{C}_{\mathrm{RS}}$ of the dependent hemithorax is about two-thirds of the contra lateral one when both lungs are ventilated in lateral decubitus (as during differential lung ventilation (DLV)). Interestingly, they also found that when switching to OLV, the static airway $\mathrm{P} / \mathrm{V}$ curve of the dependent lung (super-syringe method with inflation of $1.5-2 \mathrm{l})$, is shifted to the left and steeper, as compared to the $\mathrm{P} / \mathrm{V}$ curve obtained in the same lung during DLV, and therefore demonstrated a greater potential for lung recruitment with the application of selective PEEP. The same was observed for the esophageal P/V curve, which was shifted to the left and steeper, showing a small increase in pressure for the whole volume range. 
This suggests that during OLV the elastic recoil of the non-dependent, collapsed lung and the "compression" that it may exert on the dependent lung are lower than the elastic, expanding force in the chest wall. Our results seem to confirm these data. We measured respiratory mechanics on the dependent lung and found that on $\mathrm{OLV}_{\text {pre }}$, the chest wall contributed roughly by $30 \%$ to total respiratory system elastance whereas the lung contributed by $70 \%$. After implementing the OLA strategy, the absolute chest wall elastance did not change and therefore the decrease in total respiratory system elastance was due essentially to the decrease in lung elastance.

The reduction in inspiratory resistances observed, further suggests a more even distribution of Vt within the lung following the opening up of collapsed alveoli. Moreover, it seems reasonable to hypothesize that patients lateral position per se (surgical bed tilted in mild reverse Trendelenburg to allow a better surgical exposure, and consequent reduced abdominal content's backpressure against the diaphragm [38]), keeps chest wall mechanics invariable, as demonstrated by the unchanged $\mathrm{E}_{\mathrm{CW}}$ absolute average value after the OLA.

An additional result of the present study is the reduction of both airways and transpulmonary driving pressure following the OLA strategy. Our study protocol was not specifically designed to study driving pressures: PEEP titration was indeed performed in order to obtain the highest $C_{R S}$ and not the lowest $\Delta P$. In that case, actually, different PEEP level would probably have been reached, anyway we believe that this unanticipated result does deserve some considerations.

An increasing amount of data in literature suggests that driving pressure is a predictor of mortality in ARDS patients [44, 45], and a key mediator of the effects of various ventilatory interventions $[5,6,15] . \Delta \mathrm{P}$ is the tidal change in static trans-respiratory pressure, measured as $\mathrm{P}_{\text {PlatRS }}-\mathrm{PEEP}_{\text {tot }}$, in response to a volume-controlled breath and expresses the ratio between $\mathrm{Vt}$ and respiratory system compliance $\mathrm{Vt} / \mathrm{C}_{\mathrm{RS}}$ [45]. Many data show that reducing the alveolar cyclic collapse and reopening (atelectrauma) may protect lungs from VILI [44, 45]. Therefore, a ventilatory setting aimed at obtaining the lowest $\Delta \mathrm{P}$ is suggested as method for personalizing ventilation to individual lung physiology. The reduction in $\Delta \mathrm{P}$ following recruitment manoeuvres and/or PEEP application is also regarded as a realistic target for ventilatory adjustments. Moreover, measuring the tidal change of the real lung-distending pressure, i.e. $\Delta \mathrm{P}_{\mathrm{L}}$, is suggested as a useful tool to understand how much of the $\Delta \mathrm{P}$ is due to the lungs and how much to chest wall elastance [45]. The relationship between the two driving pressures is not thoroughly clarified; however, in our patients the parallel reduction of both driving pressures measured during volume-controlled ventilation after the OLA as compared to the ones measured before the OLA, may suggests its efficacy in terms of alveolar recruitment and, if confirmed by further studies, could corroborate the usefulness of $\Delta \mathrm{P}$ monitoring.

We also confirm that a correct hemodynamic management during the OLA strategy, does allow a safe maneuver: indeed, once the volemic status was optimized through the SVV, the OLA did not affect hemodynamic, if one excludes transient and not clinically relevant decrease in $\mathrm{CI}$ and PAM during the RM.

This study has nonetheless a few limitations. Firstly, we could not measure recruited volume, since we needed to keep respiratory mechanics measurement as short as possible in order not to prolong surgery. As regards esophageal pressure measurement, its pro and cons as a surrogate for transpulmonary pressure have been widely debated in literature [21-24], and any further discussion is beyond the scope of the present study. Nonetheless, the feasibility of $\mathrm{P}_{\mathrm{es}}$ and the signal quality could be questioned when switching from supine to lateral position, since the heart, the mediastinum, and the weight of the surrounding parenchyma could compress and modify the balloon's shape. However, we believe that these shortcomings should have been counterbalanced by having $\mathrm{P}_{\mathrm{es}}$ waveforms always collected by the same operator (MR), and the Baydur test and the filling volume test repeatedly performed within the duration of the surgery.

Although the sample population size was small, as is the rule for physiologically oriented cross over studies like ours, our data suggest that the OLA strategy could optimize oxygenation and lung mechanics during OLV. However, physiological improvements not necessarily translate in improvements in clinically meaningful outcome parameters. Recently, a large RCT in patients undergoing major abdominal surgery was not able to show any advantage of a perioperative OLA strategy over standard treatment in terms of a composite endpoint of postoperative pulmonary and systemic complications [46]. Nevertheless, due to the peculiarities of OLV, the potential impact of OLA during OLV in a large RCT is worth to investigate and the ongoing PROTHOR study (will hopefully add more definitive knowledge in this field (clinicaltrials.gov ID NCT02963025).

\section{Conclusions}

The results of our study provide evidence that decremental PEEP titration on the best $C_{R S}$, immediately after maximal lung recruitment, improves oxygenation and lung mechanics. Beyond these clear physiological benefits, the eventual impact of the OLA strategy on patients outcome is yet unknown and warrants further clinical studies. 


\section{Abbreviations}

$\%$ pred: percentage of the predicted value; ARDS: Acute Respiratory Distress Syndrome; BIS: Bi-spectral index; BMI: Body mass index; BP: Blood pressure; $\mathrm{Cl}$ : Cardiac index; $\mathrm{C}_{\mathrm{L}}$ : Lung compliance; CO: Cardiac output; $\mathrm{C}_{\mathrm{RS}}$ : Respiratory system compliance; $\mathrm{FEV}_{1}$ : Forced expiratory volume in $1 \mathrm{~s} ; \mathrm{FiO}_{2}$ : Inspiratory oxygen fraction; FVC: Forced vital capacity; HR: Heart rate; mBP: Mean arterial blood pressure; OLA: Open lung approach; OLV: One lung ventilation; $\mathrm{PaCO}_{2}$ : arterial carbon dioxide tension; $\mathrm{P}_{\mathrm{AO}, \mathrm{PLAT}}$ : Respiratory system plateau airways pressure; $\mathrm{PaO}_{2}$ : arterial oxygen tension; PEEP: Positive end expiratory pressure; $P_{\text {eso }}$ : esophageal pressure; $P_{L}:$ Transpulmonary pressure; RM: Recruitment maneuvers; RR: Respiratory rate; SV: Stroke volume; SW: Stroke volume variation; VILI: Ventilator induced lung injury; $V_{T}$ : Tidal volume; $\Delta \mathrm{P}_{R S}$ and $\Delta \mathrm{P}_{\llcorner}$: Respiratory system and transpulmonary driving pressure

\section{Acknowledgements}

None.

\section{Funding}

The study was funded by a project grant from the University of Foggia, Italy (n. 85/2009). None of the paper authors received honorarium from Companies involved in the study.

\section{Availability of data and materials}

The datasets generated and analysed during the current study are available from the corresponding author on reasonable request.

\section{Authors' contributions}

All authors have read and approved the final version. MR: Conception and design of the study, acquisition of data, analysis and interpretation of data, participated in drafting and revising the manuscript. LM: Revised the manuscript critically for important intellectual content. SG: Revised the manuscript critically for important intellectual content. AC: Participated in drafting the manuscript. SS: Participated in drafting the manuscript, analysis and interpretation of data. DD'A: Acquisition of data. FV: Acquisition of data. LT: Participated in drafting the manuscript. DL: Acquisition of data. FS: Acquisition of data. GC: Conception and design, interpretation of data, gave final approval of the version to be submitted.

\section{Ethics approval and consent to participate}

After approval of the local ethics committee (Ethics Review Board: Deni Aldo Procaccini, Maria Rosaria Castrignanò, Michele Monaco, Raffaele De Cesaris, Domenico Paleo, Romano Bucci, Francesco Morreale, Luigia Trabace, Alfonso Francesco Catanzaro, Daniela Pedà, Rosanna Stea, Simona Mastropieri, Agata Danza, Nadia Belgioioso) and written informed consent from each patient, the study was performed in consecutive patients scheduled to undergo elective lung lobectomy or resection through thoracotomy requiring OLV in the right lateral position, from February to November 2012 (ClinicalTrials.gov: NCT03435523).

\section{Consent for publication}

Not applicable.

\section{Competing interests}

The authors Savino Spadaro and Gilda Cinnella are Associate Editors for BMC Anesthesiology.

\section{Publisher's Note}

Springer Nature remains neutral with regard to jurisdictional claims in published maps and institutional affiliations.

\section{Author details}

'Department of Anesthesia and Intensive care, University of Foggia, Viale Pinto, 1-71100 Foggia, Italy. ${ }^{2}$ Department of Anesthesia and Intensive care, University of Bari, Bari, Italy. ${ }^{3}$ Department of Anesthesia and Intensive care, University of Ferrara, Ferrara, Italy. ${ }^{4}$ Department of Thoracic Surgery, University of Foggia, Foggia, Italy. ${ }^{5}$ Interdepartmental Division of Critical Care Medicine, University of Toronto, Toronto, ON, Canada.
Received: 15 May 2018 Accepted: 19 October 2018

Published online: 31 October 2018

\section{References}

1. Park SH, Jeon YT, Hwang JW, Do SH, Kim JH, Park HP. A preemptive alveolar recruitment strategy before one-lung ventilation improves arterial oxygenation in patients undergoing thoracic surgery: a prospective randomised study. Eur J Anaesthesiol. 2011;28(4):298-302.

2. $\mathrm{Ng} \mathrm{A}$, Swanevelder J. Hypoxaemia associated with one-lung anaesthesia: new discoveries in ventilation and perfusion. Br J Anaesth. 2011;106(6):761-3. https:/doi.org/10.1093/bja/aer113.

3. Lohser J. Evidence-based Management of one-Lung Ventilation. Anesthesiology Clin. 2008;26:241-72. https://doi.org/10.1016/.anclin.2008.01.011.

4. Hoftman N, Canales C, Leduc M, Mahajan A. Positive end expiratory pressure during one-lung ventilation: selecting ideal patients and ventilator settings with the aim of improving arterial oxygenation. Ann Card Anaesth. 2011;14(3):183-7. https://doi.org/10.4103/0971-9784.83991.

5. Borges JB, Senturk M, Ahlgren O, Hedenstierna G, Larsson A. Open lung in lateral decubitus with differential selective positive end-expiratory pressure in an experimental model of early acute respiratory distress syndrome. Crit Care Med. 2015;43(10):e404-11. https://doi.org/10.1097/CCM. 0000000000001143

6. Cinnella G, Grasso S, Natale C, Sollitto F, Cacciapaglia M, Angiolillo M, Pavone G, Mirabella L, Dambrosio M. Physiological effects of a lungrecruiting strategy applied during one-lung ventilation. Acta Anaesthesiol Scand. 2008:52:766-75. https://doi.org/10.1111/j.1399-6576.2008.01652.x.

7. Gama de Abreu M, Heintz M, Heller A, Széchényi R, Albrecht DM, Koch T. One-lung ventilation with high tidal volumes and zero positive endexpiratory pressure is injurious in the isolated rabbit lung model. Anesth Analg. 2003:96:220-8.

8. Slinger P. Pro: low tidal volume is indicated during one-lung ventilation. Cardiovasc Anesth. 2006;103:2. https://doi.org/10.1213/01.ane.0000223701. 24874.c8.

9. Unzueta C, Tusman G, Suarez-Sipmann F, Bohm S, Moral V. Alveolar recruitment improves ventilation during thoracic surgery: a randomized controlled trial. Br J Anaesth. 2006;108(3):517-24. https://doi.org/10.1093/ bja/aer415.

10. Michelet $P$, Blayac D, Vincent A, D'journo X-B, Perrin G, Badier M, Thomas $P$, Bregeon F. How do COPD and healthy-lung patients tolerate the reduced volume ventilation strategy during OLV ventilation. Acta Anaesthesiol Scand. 2010;54:1128-36. https://doi.org/10.1111/j.1399-6576.2010.02281.x.

11. Ferrando C, Mugarra A, Gutierrez A, Carbonell JA, García M, Soro M, Tusman G, Belda FJ. Setting individualized positive end-expiratory pressure level with a positive end-expiratory pressure decrement trial after a recruitment maneuver improves oxygenation and lung mechanics during one-lung ventilation. Anesth Analg. 2014;118:657-65.

12. Slinger PD, Kruger M, McRae K, Winton T. Relation of the static compliance curve and positive end-expiratory pressure to oxygenation during one-lung ventilation. Anesthesiology. 2001;95:1096-102.

13. Gattinoni L, Caironi P, Cressoni M, Chiumello D, Ranieri VM, Quintel M, Russo S, Patroniti N, Cornejo R, Bugedo G. Lung recruitment in patients with the acute respiratory distress syndrome. N Engl J Med. 2006; 27;354(17):1775-86.

14. Pepe PE, Hudson LD, Carrico CJ. Early application of positive end-expiratory pressure in patients at risk for the adult respiratory-distress syndrome. $\mathrm{N}$ Engl J Med. 1984;311(5):281-6.

15. Cinnella G, Grasso S, Spadaro S, Rauseo M, Mirabella L, Salatto P, De Capraris A, Nappi L, Greco P, Dambrosio M. Effects of Recruitment Maneuver and Positive End-expiratory Pressure on Respiratory Mechanics and Transpulmonary Pressure during Laparoscopic Surgery. Anesthesiology. 2013;118:114-22.

16. Garutti I, Martinez G, Cruz P, Piñeiro P, Olmedilla L, de la Gala F. The Impact of Lung Recruitment on Hemodynamics During One-Lung Ventilation. J Cardiothorac Vasc Anesth. 2009;23(4):506-8. https://doi.org/10.1053/j.jvca. 2008.12.023.

17. Benes J, Chytra I, Altmann P, Hluchy M, Kasal E, Svitak R, Pradl R, Stepan M. Intraoperative fluid optimization using stroke volume variation in high risk surgical patients: results of prospective randomized study. Crit Care. 2010; 14(3):R118. https://doi.org/10.1186/cc9070.

18. Tusman G, Böhm SH, Melkun F, Staltari D, Quinzio C, Nador C, Turchetto E. Alveolar recruitment strategy increases arterial oxygenation during one-lung ventilation. Ann Thorac Surg. 2002;73:1204-9. 
19. Tusman G, Bohm SH, Sipmann FS, Maisch S. Lung recruitment improves the efficiency of ventilation and gas exchange during one-lung ventilation anesthesia. Anesth Analg. 2004;98:1604-9.

20. Talmor D, Sarge T, Malhotra A, O'Donnell CR, Ritz R, Lisbon A, Novack V, Loring $\mathrm{SH}$. Mechanical ventilation guided by esophageal pressure in acute lung injury. N Engl J Med. 2008;359:2095-104. https://doi.org/10.1056/ NEJMoa0708638.

21. Akoumianaki E, Maggiore SM, Valenza F, Bellani G, Jubran A, Loring SH, Pelosi P, Talmor D, Grasso S, Chiumello D, Guérin C, Patroniti N, Ranieri VM, Gattinoni L, Nava S, Terragni PP, Pesenti A, Tobin M, Mancebo J, Brochard L. PLeUral pressure working Group (PLUG_Acute Respiratory Failure section of the European Society of Intensive Care Medicine). The application of esophageal pressure measurement in patients with respiratory failure. Am J Respir Crit Care Med. 2014;189:520-31.

22. Chiumello D, Cressoni M, Colombo A, Babini G, Brioni M, Crimella F, Lundin $S$, Stenqvist $O$, Gattinoni L. The assessment of transpulmonary pressure in mechanically ventilated ARDS patients. Intensive Care Med. 2014;40(11): 1670-8. https://doi.org/10.1007/s00134-014-3415-4.

23. Chiumello D, Consonni D, Coppola S, Froio S, Crimella F, Colombo A. The occlusion tests and end-expiratory esophageal pressure: measurements and comparison in controlled and assisted ventilation. Ann Intensive Care. 2016; 6(1):13.

24. Mauri T, Yoshida T, Bellani G, Goligher EC, Carteaux G, Rittayamai N, Mojoli F, Chiumello D, Piquilloud L, Grasso S, Jubran A, Laghi F, Magder S, Pesent A, Loring S, Gattinoni L, Talmor D, Blanch L, Amato M, Chen L, Brochard L, Mancebo J. PLeUral pressure working Group (PLUG_Acute Respiratory Failure section of the European Society of Intensive Care Medicine). Esophageal and transpulmonary pressure in the clinical setting: meaning, usefulness and perspectives. Intensive Care Med. 2016;42(9):1360-73. https://doi.org/10.1007/s00134-016-4400-x.

25. Bland JM, Altman DG. Measuring agreement in method comparison studies. Stat Methods Med Res. 1999;8:135-60.

26. Bland JM, Altman DG. Statistical methods for assessing agreement between two methods of clinical measurement. Lancet 1986; 8;1 (8476):307-10.

27. Benumof $\mathrm{J}$. Conventional and differential lung management of one-lung ventilation. In: Benumof $J$, editor. Anesthesia for thoracic surgery. Philadelphia: WB Saunders; 1995. p. 406-31.

28. Kozian A, Schilling T, Schütze $H$, Senturk M, Hachenberg T, Hedenstierna $G$. Ventilatory protective strategies during thoracic surgery: effects of alveolar recruitment maneuver and low-tidal volume ventilation on lung density distribution. Anesthesiology. 2011;114:1025-35.

29. Schilling T, Kozian A, Huth C, et al. The pulmonary immune effects of mechanical ventilation in patients undergoing thoracic surgery. Anesth Analg. 2005;101:957-65.

30. Shen $Y$, Zhong M, Wu W, Wang H, Feng M, Tan L, Wang Q. The impact of tidal volume on pulmonary complications following minimally invasive esophagectomy: a randomized and controlled study. J Thorac Cardiovasc Surg. 2013;146:1267-73.

31. Wrigge $H$, Uhlig U, Zinserling J, Behrends-Callsen E, Ottersbach G, Fischer M, Uhlig S, Putensen $C$. The effects of different ventilatory settings on pulmonary and systemic inflammatory responses during major surgery. Anesth Analg. 2004;98:775-81.

32. Végh T, Juhász M, Szatmári S, Enyedi A, Sessler DI, Szegedi LL, Fülesdi B. Effects of different tidal volumes for one-lung ventilation on oxygenation with open chest condition and surgical manipulation: a randomised crossover trial. Minerva Anestesiol. 2013;79:24-32.

33. Michelet $P, D^{\prime}$ Journo XB, Roch A, Doddoli C, Marin V, Papazian L, Decamps I, Bregeon F, Thomas P, Auffray JP. Protective ventilation influences systemic inflammation after esophagectomy: a randomized controlled study. Anesthesiology. 2006;105:911-9.

34. Sutherasan $Y$, D'Antini D, Pelosi P. Advances in ventilator-associated lung injury: prevention is the target. Expert Rev Respir Med. 2014;8(2):233-48. https://doi.org/10.1586/17476348.2014.890519.

35. Qutub H, El-Tahan MR, Mowafi HA, El Ghoneimy YF, Regal MA, Al Saflan AA. Effect of tidal volume on extravascular lung water content during one-lung ventilation for videoassisted thoracoscopic surgery: a randomised, controlled trial. Eur J Anaesthesiol. 2014;31:466-73.

36. Verhage RJ, Boone J, Rijkers GT, Cromheecke GJ, Kroese AC, Weijs TJ, Borel Rinkes $\mathrm{H}$, van Hillegersberg $\mathrm{R}$. Reduced local immune response with continuous positive airway pressure during one-lung ventilation for oesophagectomy. Br J Anaesth. 2014;112:920-8.
37. Fujiwara M, Abe K, Mashimo T. The effect of positive endexpiratory pressure and continuous positive airway pressure on the oxygenation and shunt fraction during one-lung ventilation with propofol anesthesia. J Clin Anesthesia. 2001;13:473-7.

38. Lohser J, Slinger P. Lung injury after one-lung ventilation: a review of the pathophysiologic mechanisms affecting the ventilated and the collapsed lung. Anesth Analg. 2015;121(2):302-18. https://doi.org/10.1213/ANE. 0000000000000808 .

39. Spadaro S, Grasso S, Karbing DS, Fogagnolo A, Contoli M, Bollini G, Ragazzi R, Cinnella G, Verri M, Cavallesco NG, Rees SE, Volta CA. Physiologic evaluation of ventilation perfusion mismatch and respiratory mechanics at different positive end-expiratory pressure in patients undergoing protective one-lung ventilation. Anesthesiology. 2018 Mar;128(3):531-8. https://doi.org/ 10.1097/ALN.0000000000002011.

40. Cinnella G, Grasso S, Raimondo P, D'Antini D, Mirabella L, Rauseo M, Dambrosio M. Physiological effects of the open lung approach in patients with early, mild, diffuse acute respiratory distress syndrome: an electrical impedance tomography study. Anesthesiology. 2015 Nov;123(5):1113-21. https://doi.org/10.1097/ALN.0000000000000862.

41. Nieman GF, Satalin J, Andrews P, Aiash H, Habashi NM, Gatto LA. Personalizing mechanical ventilation according to physiologic parameters to stabilize alveoli and minimize ventilator induced lung injury (VILI). Intensive Care Med Exp. 2017;5(1):8. https://doi.org/10.1186/s40635-017-0121-x.

42. Washko GR, O'Donnell CR, Loring SHJ. Volume-related and volumeindependent effects of posture on esophageal and transpulmonary pressures in healthy subjects. Appl Physiol (1985). 2006;100(3):753-8.

43. Klingstedt C, Baehrendtz S, Bindslev L, Hedenstierna G. Lung and chest wall mechanics during differential ventilation with selective PEEP. Acta Anaesthesiol Scand. 1985;29(7):716-21.

44. Serpa Neto A, Hemmes SN, Barbas CS, Beiderlinden M, FernandezBustamante A, Futier E, Hollmann MW, Jaber S, Kozian A, Licker M, Lin WQ, Moine P, Scavonetto F, Schilling T, Selmo G, Severgnini P, Sprung J, Treschan T, Unzueta C, Weingarten TN, Wolthuis EK, Wrigge H, Gama de Abreu M, Pelosi P, Schultz MJ. PROVE Network investigators. Incidence of mortality and morbidity related to postoperative lung injury in patients who have undergone abdominal or thoracic surgery: a systematic review and meta-analysis. Lancet Respir Med. 2014;2(12):1007-15. https://doi.org/10. 1016/S2213-2600(14)70228-0

45. Amato MB, Meade MO, Slutsky AS, Brochard L, Costa EL, Schoenfeld DA, Stewart TE, Briel M, Talmor D, Mercat A, Richard JC, Carvalho CR, Brower RG. Driving pressure and survival in the acute respiratory distress syndrome. $\mathrm{N}$ Engl J Med. 2015;372:747-55. https://doi.org/10.1056/NEJMsa1410639.

46. Ferrando C, Soro M, Unzueta C, Suarez-Sipmann F, Canet J, Librero J, Pozo N, Peiró S, Llombart A, León I, India I, Aldecoa C, Díaz-Cambronero O, Pestaña D, Redondo FJ, Garutti I, Balust J, García Jl, Ibáñez M, Granell M, Rodríguez A, Gallego L, de la Matta M, Gonzalez R, Brunelli A, García J, Rovira L, Barrios F, Torres V, Hernández S, Gracia E, Giné M, García M, García N, Miguel L, Sánchez S, Piñeiro P, Pujol R, García-Del-Valle S, Valdivia J, Hernández MJ, Padrón O, Colás A, Puig J, Azparren G, Tusman G, Villar J, Belda J. Individualized PeRioperative Open-lung VEntilation (iPROVE) Network. Individualised perioperative open-lung approach versus standard protective ventilation in abdominal surgery (iPROVE): a randomised controlled trial. Lancet Respir Med. 2018;6(3):193-203. https://doi.org/10. 1016/S2213-2600(18)30024-9 Epub 2018 Jan 19.

\section{Ready to submit your research? Choose BMC and benefit from:}

- fast, convenient online submission

- thorough peer review by experienced researchers in your field

- rapid publication on acceptance

- support for research data, including large and complex data types

- gold Open Access which fosters wider collaboration and increased citations

- maximum visibility for your research: over $100 \mathrm{M}$ website views per year

At BMC, research is always in progress.

Learn more biomedcentral.com/submissions 